\title{
The effect of postoperative epidural analgesia in women possessing severe gestational hypertension undergoing cesarean delivery
}

\author{
Misao Satomi, Yoshie Hiraizumi, Hidetaka Onodera, Shunji Suzuki
}

Department of Obstetrics and Gynecology, Japanese Red Cross Katsushika Maternity Hospital, Tokyo, Japan. Email: $\underline{\operatorname{czg} 83542 @ \text { mopera.ne.jp }}$

Received 30 August 2011; revised 30 September 2011; accepted 15 October 2011.

\begin{abstract}
Introduction: The purpose of this study was to examine the clinical usefulness of postoperative epidural analgesia in patients possessing severe gestational hypertension after Cesarean delivery. Methods: We reviewed the obstetric records of 99 patients possessing severe gestational hypertension undergoing singleton Cesarean delivery at $\geq 22$ weeks' gestation. Thirty patients were received continuous epidural analgesia with $0.2 \%$ ropivacaine for pain relief after Cesarean delivery with spinal anesthesia, 69 patients were not received epidural analgesia after Cesarean delivery with spinal anesthesia. Results: During the preoperative period, there were no measurable differences in the diastolic blood pressure between the 2 groups $(108 \pm 7$ vs. $106 \mathrm{mmHg} \pm 10 \mathrm{mmHg}, p=0.29)$. The diastolic blood pressure at 2 and 4 hours after Cesarean section in the epidural analgesia group were significantly lower than those in the non-epidural group ( 2 hours after Cesarean section: $88 \pm 13$ vs. $95 \mathrm{mmHg}$ $\pm 8 \mathrm{mmHg}, p<0.01 ; 4$ hours after Cesarean section: 92 \pm 15 vs. $102 \mathrm{mmHg} \pm 9 \mathrm{mmHg}, p<0.01)$. Conclusions: The current results indicated that the postoperative epidural analgesia can inhibit the rise in diastolic blood pressure in patients possessing severe gestational hypertension after Cesarean delivery. This electronic document is a "live" template. The various components of your paper [title, text, heads, etc.] are already defined on the style sheet, as illustrated by the portions given in this document.
\end{abstract}

Keywords: Postoperative Epidural Analgesia; Severe Gestational Hypertension; Ropivacaine; Cesarean Delivery

\section{INTRODUCTION}

Recently, $0.5 \%$ bupivacaine has been widely used for spinal anesthesia for Cesarean delivery, because it is lon- ger-acting than the drugs used previously such as dibucaine and tetracaine $[1,2]$. For many years, spinal anesthesia had not been recommended as an anesthetic technique for Cesarean delivery with gestational hypertension to avoid critical hypotension, but recently spinal anesthesia is getting popular for Cesarean delivery $[2,3]$. Continuous epidural analgesia now plays one of important roles in postoperative pain control, and the clinical usefulness of epidural analgesia after Cesarean delivery has been reported for healthy pregnant women $[1,3-5]$. In Japan, $0.2 \%$ ropivacaine has been sometimes administrated for continuous epidural analgesia to decrease postoperative pain after Cesarean section [1]. To our knowledge, however, there have been no hemodynamic investtigations concerning the effect of postoperative epidural analgesia on severely preeclamptic patients after Cesarean delivery. The aim of this study was to examine the clinical usefulness of postoperative epidural analgesia in patients possessing severe gestational hypertension after Cesarean delivery.

\section{PATIENTS AND METHODS}

We reviewed the obstetric records of 99 Japanese patients possessing severe gestational hypertension undergoing singleton Cesarean delivery at $\geq 22$ weeks' gestation managed at the Japanese Red Cross Katsushika Maternity Hospital between 2008 and 2010. There were no patients taking antihypertensive medications preoperatively. During this period, 30 patients were received continuous epidural analgesia with $0.2 \%$ ropivacaine for pain relief after Cesarean delivery with spinal anesthesia, 69 patients were not received epidural analgesia after Cesarean delivery with spinal anesthesia. This retrospective study was approved by the Ethics Committee of Japanese Red Cross Katsushika Maternity Hospital. Demographic information and the characteristics of severe gestational hypertension were extracted from the patient charts. Patients with multiple pregnancy, chronic hyper- 
tension, renal disease and systemic illnesses were excluded. Severe gestational hypertension was defined as blood pressure $\geq 160 / 110 \mathrm{mmHg}$ measured on 2 or more occasions at least six hours apart with the patient at rest. HELLP syndrome was defined as a syndrome of intravascular hemolysis $(\mathrm{H})$, elevated liver enzymes (EL) and low platelets count (LP) previously reported.

In all cases, after fluid administration of $1000 \mathrm{ml}$ of lactated Ringer's solution, a 25-gauge or 23-gauge spinal needle was placed at the L2-3 or L3-4 interspace with the patient in the lateral decubitus position. After observing the flow of cerebrospinal fluid, $1.7 \mathrm{ml}-2.5 \mathrm{ml}$ of $0.5 \%$ hypervaric bupivacaine was injected into the subarachnoid space. The dose of $0.5 \%$ hypervaric bupivacaine was determined mainly based on the maternal height. In the postoperative epidural analgesia group, after spinal injection the epidural catheter was placed with an 18-gauge Tuohy needle in the L1-2 or Th12-L1 interspace for postoperative analgesia. About 10 minutes before the end of surgery, $100 \mathrm{ml}$ of $0.2 \%$ ropivacaine was administered through the epidural catheter at a rate of $5 \mathrm{ml} /$ minute for postoperative pain relief. In our department, bolus administration of an epidural initial dose is thought to be unnecessary based on a previous study by Hongo et al. [1] At anytime after surgery, the patient could be given $50 \mathrm{mg}$ flurbiprofen axetil $i v$ or $15 \mathrm{mg}$ pentazocine $i v$ if she experienced pain or discomfort. If the systoric blood pressure increased over 160 or the diastolic blood pressure increased over $110 \mathrm{mmHg}$ on 2 or more occasions at least 1 hour - 2 hours apart, a continuous intravenous infusion of nicardipine $\mathrm{HCl}$ was started.

Data are presented as mean \pm SD or number (\%). For statistical analysis, the $X^{2}$ test for categorical variables and the Student's $t$-test for continuous variables were used. Differences with $P<0.05$ were considered significant.

\section{RESULTS}

Table 1 shows the clinical characteristics of patients possessing severe gestational hypertension with and without postoperative epidural analgesia. In this study, there were no measurable differences in the bupivacaine dose for spinal anesthesia between the 2 groups (epidural analgesia group: $2.1 \mathrm{ml} \pm 0.2 \mathrm{ml}$ vs. non-epidural group: $2.2 \mathrm{ml} \pm 0.2 \mathrm{ml}, p=0.33$ ). There were no significant differences in maternal age, parity, height, body weight, systolic and diastolic blood pressure, incidences of proteinuria during preoperative period, HELLP syndrome or eclampsia, surgical duration, maternal blood loss during Cesarean section and duration of postoperative hospitalization between the 2 groups. In this study, the

Table 1. The clinical characteristics of patients possessing severe gestational hypertension with and without postoperative epidural analgesia.

\begin{tabular}{lccc}
\hline Postoperative epidural analgesia & $(-)$ & $(+)$ & P value \\
\hline Maternal age (years) & $(\mathrm{n}=69)$ & $(\mathrm{n}=30)$ & 0.34 \\
Nulliparity & $35 \pm 4$ & $34 \pm 5$ & 0.34 \\
Maternal height (cm) & $46(67 \%)$ & $17(57 \%)$ & 0.09 \\
Maternal weight at delivery (kg) & $159 \pm 6$ & $157 \pm 5$ & 0.78 \\
Gestational age at delivery (weeks) & $67 \pm 13$ & $68 \pm 17$ & $<0.01$ \\
Blood pressure before surgery & $35.5 \pm 3$ & $31.9 \pm 2$ & 0.64 \\
Systolic blood pressure (mmHg) & & & 0.29 \\
Diastolic blood pressure (mmHg) & $179 \pm 11$ & $178 \pm 9$ & 0.97 \\
Proteinuria $\geq 100$ mg/dl & $106 \pm 10$ & $108 \pm 7$ & 0.91 \\
HELLP syndrome & & 1 \\
Eclampsia & $25(36 \%)$ & $11(37 \%)$ & 0.57 \\
Surgical duration (minutes) & $2(2.9 \%)$ & $1(3.3 \%)$ & 0.69 \\
Maternal blood loss during surgery (g) & $0(0 \%)$ & $0(0 \%)$ & 1 \\
Transfusion & $32 \pm 10$ & $31 \pm 7$ & $<0.01$ \\
Neonatal birth weight (g) & $650 \pm 460$ & $690 \pm 460$ & 0.08 \\
Light for gestational age infants & $0(0 \%)$ & $0(0 \%)$ & $<0.01$ \\
Apgar score at 1 minute & $2276 \pm 725$ & $1770 \pm 478$ & 0.98 \\
Apgar score at 5 minute & $14(20 \%)$ & $11(37 \%)$ & 0.99 \\
Umbilical artery pH & $8.3 \pm 1.0$ & $7.6 \pm 1.1$ & 0.09 \\
Duration of postoperative hospitalization (days) & $9.1 \pm 0.6$ & $9.1 \pm 0.3$ & $7.30 \pm 0.04$ \\
\hline Da & $7.30 \pm 0.04$ & $7.8 \pm 0.6$ & \\
\hline
\end{tabular}

${ }^{\mathrm{a}}$ Data are presented as mean \pm SD or number (\%). HELLP syndrome $=$ hemolysis, elevated liver enzymes and low platelets syndrome. 
gestational age at Cesarean delivery in the epidural analgesia group was significantly earlier than that in the non-epidural group. In addition, the neonatal birth weight and Apgar score at 1 minute in the epidural analgesia group were significantly lower than those in the nonepidural group.

Table 2 shows the infusion volume, urine volume, frequency of intravenous injection of pain-killer and intravenous infusion of nicardipine $\mathrm{HCl}$ during postoperative 24 hours in patients with and without postoperative epidural analgesia. There were no patients with postoperative urination disorder in the 2 groups. The frequency of receiving $50 \mathrm{mg}$ flurbiprofen axetil $i v$ in the epidural analgesia group was significantly lower than that in the non-epidural group. However, there was no significant difference in the rate of patients requiring intravenous infusion of nicardipine $\mathrm{HCl}$ during postoperative 24 hours between the 2 groups.

Table 3 shows the changes in systolic and diastolic blood pressure in the patients with and without postoperative epidural analgesia. During the preoperative period, there were no measurable differences in the systolic and diastolic blood pressure between the 2 groups, and there were no measurable differences in the systolic blood pressure between the 2 groups at 2 and 4 hours after Cesarean section. However, the diastolic blood pressure at 2 and 4 hours after Cesarean section in the epidural analgesia group were significantly lower than those in the non-epidural group. One day after surgery, there were no measurable differences in the blood pressure between the 2 groups with the presence of patients receiving intravenous infusion of nicardipine $\mathrm{HCl}$.

Table 2. The infusion volume, urine volume, frequency of intravenous injection of pain-killer and intravenous infusion of nicardipine $\mathrm{HCl}$ during postoperative 24 hours in patients with and without postoperative epidural analgesia.

\begin{tabular}{|c|c|c|c|}
\hline Postoperative epidural analgesia & $(-)$ & $(+)$ & $P$ value \\
\hline & $(\mathrm{n}=69)$ & $(\mathrm{n}=30)$ & \\
\hline Total infusion volume (ml) & $2650 \pm 240$ & $2720 \pm 310$ & 0.28 \\
\hline \multicolumn{4}{|l|}{ Urine volume } \\
\hline Total volume (ml) & $3020 \pm 840$ & $3200 \pm 660$ & 0.26 \\
\hline Urine volume $<1000 \mathrm{ml}$ & $0(0 \%)$ & $0(0 \%)$ & 1 \\
\hline Furosemide use & $0(0 \%)$ & $1(3.3 \%)$ & 0.13 \\
\hline \multicolumn{4}{|c|}{ Intravenous injection of pain-killer (times) } \\
\hline Flurbiprofen axetil $50 \mathrm{mg}$ & $1.9 \pm 1.1$ & $1.4 \pm 0.9$ & 0.02 \\
\hline Pentazocine $15 \mathrm{mg}$ & $2.0 \pm 1.6$ & $1.5 \pm 1.2$ & 0.09 \\
\hline
\end{tabular}

Data are presented as mean \pm SD or number $(\%)$.

Table 3. The changes in systolic and diastolic blood pressure in the patients with and without postoperative epidural analgesia.

\begin{tabular}{|c|c|c|c|}
\hline Postoperative epidural analgesia & $(-)$ & $(+)$ & $P$ value \\
\hline & $(n=69)$ & $(\mathrm{n}=30)$ & \\
\hline \multicolumn{4}{|l|}{ Duration preoperative period } \\
\hline Systolic blood pressure ( $\mathrm{mmHg}$ ) & $179 \pm 11$ & $178 \pm 9$ & 0.64 \\
\hline Diastolic blood pressure (mmHg) & $106 \pm 10$ & $108 \pm 7$ & 0.29 \\
\hline \multicolumn{4}{|l|}{ At delivery } \\
\hline Systolic blood pressure (mmHg) & $125 \pm 13$ & $129 \pm 10$ & 0.1 \\
\hline Diastolic blood pressure (mmHg) & $73 \pm 5$ & $76 \pm 10$ & 0.13 \\
\hline \multicolumn{4}{|l|}{ Two hours after surgery } \\
\hline Systolic blood pressure (mmHg) & $151 \pm 14$ & $144 \pm 17$ & 0.05 \\
\hline Diastolic blood pressure (mmHg) & $95 \pm 8$ & $88 \pm 13$ & $<0.01$ \\
\hline \multicolumn{4}{|l|}{ Four hours after surgery } \\
\hline Systolic blood pressure (mmHg) & $164 \pm 14$ & $163 \pm 22$ & 0.82 \\
\hline Diastolic blood pressure (mmHg) & $102 \pm 9$ & $92 \pm 15$ & $<0.01$ \\
\hline \multicolumn{4}{|l|}{ One day after surgery } \\
\hline Systolic blood pressure ( $\mathrm{mmHg}$ ) & $136 \pm 9$ & $133 \pm 11$ & 0.19 \\
\hline Diastolic blood pressure (mmHg) & $84 \pm 8$ & $82 \pm 9$ & 0.31 \\
\hline
\end{tabular}

Data are presented as mean $\pm \mathrm{SD}$ or number (\%). 


\section{DISCUSSION}

In this study, the epidural continuous infusion provided pain relief in severe hypertensive patients after Cesaren section as previously reported $[6,7]$. In this study, there was no significant difference in the rate of patients requiring antihypertensive agents between the patients with and without postoperative epidural analgesia because there were no significant differences in the systolic blood pressure levels between the 2 groups; however the current results indicated that the postoperative epidural analgesia can inhibit the rise in diastolic blood pressure in patients possessing severe gestational hypertension after Cesarean delivery.

In patients possessing gestational hypertension, the blood pressure has been observed to be sometimes reincreased to the severely levels after Cesarean delivery associated with the postoperative pain and the return of vascular tone following delivery $[8,9]$. This return of vascular tone has been suggested to be also related to profound fluid shifts that occur in the puerperium with a rise in intravascular volume due to mobilization of extravascular fluid $[8,9]$. Regional anesthesia-induced sympathetic blockade may be contributed to the decrease in diastolic blood pressure associate with the systemic peripheral vascular dilation in patients with severe gestational hypertension. However, the current results also indicated the sympathetic blockade with vascular dilation may not be able to prevent the fluid shifts associated with the re-increased systolic blood pressure in patients possessing gestational hypertension although there were no significant differences in the urine volume during postoperative 24 hours.

We know that there are some limitations in this retrospective study. Firstly, this may be a small study. Secondly, in this study the parturient required Cesarean delivery at earlier gestation received epidural analgesia more frequently. We cannot explain the reason for this tendency well; however it may also support the efficacy of postoperative epidural analgesia inhibiting the rise in blood pressure because hypertensive disorders developing at earlier gestation have been reported to tend to be severe [10]. Otherwise, a circulating blood volume maybe smaller in the epidural group than that in the nonepidural group and the smaller volume may explain the decreased diastolic pressure in the epidural group after Cesarean delivery. Therefore, a prospective study to clear this difference may be needed.

The postoperative epidural analgesia may be useful in the management of patient with severe gestational hypertension after Cesarean delivery, because adequate control of diastolic blood pressure is important to pre- vent systemic organ dysfunction in severe gestational hypertension [11]. However, further studies may be needed concerning the changes in systolic blood pressure.

\section{REFERENCES}

[1] Hongo, T., Kitamura, A., Yokozuka, M., Kim, C. and Sakamoto, A. (2006) An epidural initial dose in unnecessary in combined spinal epidural anesthesia for Caesarean section. Journal of Nippon Medical Scool, 73, 70-74. doi: $10.1272 /$ jnms. 73.70

[2] Suzuki, H., Ogawa, S., Hanaoka, K., Kugimiya, T., Yokoyama, K., Isshiki, A., Hosoyamada, A., Kikuchi, H. and Numata, K. (1998) Clinical study of AJ-007 (bupivacaine) in spinal anesthesia - investigation of clinical dosage of isobaric and hyperbaric formulations (in Japanese). Masui, 47, 447-465.

[3] Block, B.M., Lieu, S.S., Rowlingson, A.J., Cowan, A.R., Cowan, J.A. Jr. and Wu, C.L. (2003) Efficacy of postoperative epidural analgesia. Journal of the American Medical Association, 290, 2455-2463.

doi:10.1001/jama.290.18.2455

[4] Mendez, R., Eisenach, J.C. and Kashtan, K. (1990) Epidural clonidine analgesia after Cesarean section. Anesthesiology, 73, 848-852. doi:10.1097/00000542-199011000-00009

[5] Jens-Christian, S., Adam, K., Joerg, Z., Joachim, N., Andreas, H. and Rudolf, H. (2009) Effects of spinal anaesthesia versus epidural anaesthesia for caesarean section on postoperative analgesic consumption and postoperative pain. European Journal of Anaesthesiology, 26, 5259. doi:10.1097/EJA.0b013e328318c639

[6] Hood, D.D. and Curry, R. (1990) Spinal versus epidural anesthesia for Cesarean section in severely preeclamptic patients. Anesthesiology, 90, 1276-1282. doi:10.1097/00000542-199905000-00009

[7] Visalyaputa, S., Rodanant, O., Somboonviboon, W., Tantivitayatan, K., Thienthong, S. and Saengchote, W. (2005) Spinal versus epidural anesthesia for Cesarean delivery in severe preeclampsia: A prospective randomized multicenter study. Anesthesia and Analgesia, 101, 862-868. doi:10.1213/01.ANE.0000160535.95678.34

[8] Ferrazani, S., DeCarolis, S., Pomini, F., Testa, A.C., Mastomarino, C. and Caruso, A. (1994) The duration of hypertension in the puerperium of preeclamptic women: Relationship with renal impairment and week of delivery. American Journal of Obstetrics and Gynecology, 171, 506-512.

[9] Walters, B.N., Thompson, M.E., Lee, A. and de Swiet, M. (1986) Blood pressure in the puerperium. Clinical Science (Lond), 71, 589-594.

[10] Paruk, F. and Moodley, J. (2000) Maternal and neonatal outcome in early- and late-onset pre-eclampsia. Seminars in Neonatology, 5, 197-207. doi:10.1053/siny.2000.0023

[11] Von Dadelszen, P., Menzies, J., Gilgoff, S., Xie, F., Douglas, M.J., Sawchuck, D. and Magee, L.A. (2007) Evidence-based management for preeclampsia. Frontiers in Bioscience, 12, 2876-2889. doi:10.2741/2279 